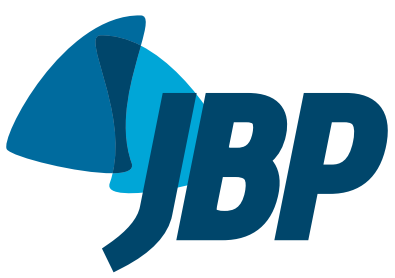

\title{
Choosing wisely between randomized controlled trials and observational designs in studies about interventions
}

\author{
Juliana Carvalho Ferreira ${ }^{1,2}$, Cecilia Maria Patino ${ }^{2,3}$
}

Randomized controlled trials (RCTs) are the gold standard for evaluating the efficacy of interventions, because they avoid key sources of bias by randomly allocating participants to the treatment or control. That feature of the study design makes RCTs the highest ranked type of study within the Evidence-Based Medicine framework grading system. However, not all questions about health interventions can be answered with an RCT. Observational studies may be more appropriate to study certain aspects about interventions and thus complement RCTs.

In some situations, it is unfeasible or unethical to randomize patients to a treatment, such as a surgical intervention, if surgeons are uncomfortable performing an unfamiliar procedure. In addition, observational studies are better suited to evaluate the incidence of adverse events of interventions because they have less strict inclusion and exclusion criteria, which allows a broader spectrum of the target population to be included. While RCTs are usually the best option to test efficacy (the effect of the intervention under ideal conditions), observational studies are a valuable option to evaluate effectiveness (the effect of an intervention in real life).

Some advantages of observational studies include the following: they are usually less expensive than RCTs, they have no ethical roadblocks in assigning participants to treatment or control groups, and placebos are rarely used (Table 1).

\section{CHOOSING WISELY}

The choice between an observational study and an RCT should be based on the specific research question. Observational designs are appropriate when it is reasonable to assume that characteristics that influence clinicians to choose a given intervention are not related to the study outcome. For example, in a comparison between the impact of radiosurgery and that of surgical lung resection on the survival of lung cancer patients, an observational study would not be appropriate, because the choice between radiosurgery and lung resection is influenced by tumor size and patient performance status, which also influence survival independently of the treatment option. In contrast, observational studies are often used to study the effectiveness of vaccination to protect against infectious diseases, because the characteristics that influence the decision to get vaccinated are not major determinants of the risk of being infected.

\section{MINIMIZING BIAS}

When conducting observational studies to test interventions, the investigator needs to design strategies to minimize bias resulting from imbalances in competing risk factors (confounders) across the intervention and control groups. In the design phase, a typical strategy involves measuring known confounders at baseline and later adjusting for those confounders during the analysis phase by using multivariable models. Another strategy includes combining confounding variables associated with the intervention and creating a new variable, called a propensity score, that can be used, for example, to match participants at baseline or adjust for confounders during analysis. However, the efficiency of such methods is limited to known and adequately measured confounders.

\section{BEYOND STUDY DESIGN}

When evaluating the medical literature, clinicians should consider not only the design (RCT or observational) but also the quality of a given study. RCTs and observational trials both contribute to advancing knowledge in health care, which can guide clinical decision-making and public health policy.

Table 1. Comparison between randomized controlled trials and observational studies.

\begin{tabular}{|c|c|c|}
\hline Aspect & RCTs & $\begin{array}{l}\text { Observational } \\
\text { studies }\end{array}$ \\
\hline Randomization & Yes & No \\
\hline Risk of selection bias & Low & Can be high \\
\hline $\begin{array}{l}\text { Risk of imbalances in baseline } \\
\text { risk factors }\end{array}$ & Low & High \\
\hline Cost & ++++ & ++ \\
\hline Complexity & ++++ & ++ \\
\hline Duration & ++ & ++++ \\
\hline $\begin{array}{l}\text { Appropriate for evaluating } \\
\text { efficacy }\end{array}$ & ++++ & ++ to +++ \\
\hline $\begin{array}{l}\text { Appropriate for evaluating } \\
\text { effectiveness }\end{array}$ & + & +++ \\
\hline $\begin{array}{l}\text { Appropriate for identifying } \\
\text { adverse events }\end{array}$ & ++ to +++ & ++++ \\
\hline
\end{tabular}

RCTs: randomized controlled trials.

\section{RECOMMENDED READING}

\footnotetext{
Concato, J, Shah N, Horwitz RI. Randomized, controlled trials, observational studies, and the hierarchy of research designs. N Engl J Med. 2000:342(25):1887-92. http://dx.doi.org/10.1056/ NEJM200006223422507
}

2. Black N. Why we need observational studies to evaluate the effectiveness of health care. BMJ. 1996;312(7040):1215-8. http://dx.doi. org/10.1136/bmj.312.7040.1215

1. Divisão de Pneumologia, Instituto do Coração - InCor - Hospital das Clínicas, Faculdade de Medicina, Universidade de São Paulo (SP) Brasil.

2. Methods in Epidemiologic, Clinical and Operations Research-MECOR-program, American Thoracic Society/Asociación Latinoamericana del Tórax.

3. Department of Preventive Medicine, Keck School of Medicine, University of Southern California, Los Angeles (CA) USA. 